\title{
Cyanide-modified Pt(111): structure, stability and hydrogen adsorption
}

\author{
María Escudero-Escribano $^{a}$, Germán J. Soldano ${ }^{b}$, Paola Quaino ${ }^{b, c}{ }^{c}$ Martín E. Zoloff Michoff ${ }^{d}$, \\ Ezequiel P. M. Leiva ${ }^{d}$, Wolfgang Schmickler ${ }^{b}$, and Ángel Cuesta ${ }^{\mathrm{a}, *}$ \\ anstituto de Química Física “Rocasolano”, CSIC, C. Serrano, 119, E-28006 Madrid, Spain \\ ${ }^{\mathrm{b}}$ Institut für Theoretische Chemie, Universitat Ulm, D-89069 Ulm, Germany \\ ${ }^{\mathrm{c}}$ PRELINE, Facultad de Ingeniería Química, Universidad Nacional del Litoral, 3000, Santa Fe, \\ Argentina. \\ ${ }^{\mathrm{d}}$ INFIQC, Departamento de Matemática y Física, Facultad de Ciencias Químicas, Universidad \\ Nacional de Córdoba, Córdoba, Argentina \\ *Corresponding autor. \\ E-mail address: a.cuesta@iqfr.csic.es
}

\begin{abstract}
Cyanide-modified $\operatorname{Pt}(111)$ surfaces have been recently used to study atomic-ensemble effects in electrocatalysis. These studies have been based on the assumption that cyanide acts as a third body, blocking some surface sites but leaving the electronic properties of the surrounding ones unaltered, although this is in apparent contradiction with the observation of a positive shift of $0.2 \mathrm{~V}$ in the onset of hydrogen adsorption on cyanide-modified $\operatorname{Pt}(111)$ electrodes, as compared with clean $\mathrm{Pt}(111)$. We have performed theoretical calculations in order to provide support to this assumption and explain the positive shift in the onset of hydrogen adsorption, which is shown to be due to the formation of $\mathrm{CNH}_{\mathrm{ad}}$.
\end{abstract}

Keywords: cyanide-modified Pt(111); DFT; hydrogen adsorption

\section{Introduction}

The adsorption of cyanide on single-crystal platinum electrodes has been intensively investigated over the last two decades, partly because cyanide and carbon monoxide are isoelectronic [1-10]. Cyanide is irreversibly adsorbed on Pt single-crystal electrodes: the case of $\operatorname{Pt}(111)$ is particularly interesting, due to the spontaneous formation, upon immersion of $\operatorname{Pt}(111)$ in a cyanide-containing solution, of an ordered $(2 \sqrt{3} \times 2 \sqrt{ } 3) R 30^{\circ}$ structure $[1,4,5]$ which extends over the whole electrode surface and is composed of hexagonally packed hexagons, each of them containing six cyanide groups adsorbed on top of a hexagon of Pt surface atoms surrounding a free Pt atom. This structure was observed for the first time using low-energy electron diffraction (LEED) 
by Hubbard and co-workers [1], who demonstrated that the $(2 \sqrt{3} \times 2 \sqrt{ } 3) R 30^{\circ}$ structure formed by adsorbed cyanide on $\mathrm{Pt}(111)$ resists electrode emersion and transfer into a UHV chamber, which indicates a very strong adsorption. The atomic, real space structure could later be elucidated by electrochemical STM [4,5]. Although most STM experiments were performed in alkaline solutions [4,5], Itaya and co-workers [5] observed the same structure in acidic solutions.

Cyanide adsorption on $\mathrm{Pt}(111)$ has been intensively studied in acidic solutions by Huerta et al. [6-10], who demonstrated, by means of cyclic voltammetry, that cyanide-covered $\mathrm{Pt}(111)$ could be considered as a chemically-modified electrode [6]. The cyanide adlayer on $\operatorname{Pt}(111)$ is remarkably stable, no change being observed upon repetitive cycling between 0.05 and $1.10 \mathrm{~V}$. Cyclic voltammograms (CVs) of cyanidemodified $\mathrm{Pt}(111)$ in $\mathrm{HClO}_{4}$ and in $\mathrm{H}_{2} \mathrm{SO}_{4}$ solutions are qualitatively very similar, indicating the insensitivity of the chemically-modified surface to the anions present in the supporting electrolyte, i.e., adsorbed cyanide acts as a third-body, which selectively blocks the sites necessary for the adsorption of tetrahedral anions, such as sulphate, on $\mathrm{Pt}$, while leaving unaffected the $\mathrm{CN}$-free $\mathrm{Pt}$ atoms onto which $\mathrm{OH}, \mathrm{CO}$ or $\mathrm{NO}$ [10-12] can adsorb.

A very appropriate way to study the role of geometric atomic ensembles in electrocatalysis is to modify the surface in such a way that only one kind of site is removed without modifying the electronic structure of the rest of the surface (the siteknockout strategy [13]). Interestingly, all the sites composed of three contiguous Pt atoms are absent on cyanide-modified $\mathrm{Pt}(111)$ and, as a consequence, adsorption at three-fold hollow sites [12,14] or reaction steps requiring three contiguous $\mathrm{Pt}$ atoms $[15,16]$ are inhibited. These chemically-modified surfaces have been used to demonstrate that the dehydrogenation of methanol [15] and the dehydration of formic acid [16] to adsorbed carbon monoxide require at least three contiguous Pt atoms. Furthermore, modification of $\operatorname{Pt}(111)$ with cyanide results in a huge enhancement of the catalytic activity for the ORR in sulfuric and phosphoric acid solutions, because the sites necessary for the adsorption of the tetragonal anions of these acids have been blocked [14]. In all the previous cases, it was assumed that significant simultaneous electronic effects were absent, although we lacked a clear and definitive proof. Cyanidemodified Pt(111) surfaces can also be used to study the role of non-covalent interactions at the electrochemical double layer [17], and cations non-covalently attached to the electrode surface can be used as precursors for surface nanostructuring [18,19]. 
Theoretical studies concerning the spatial and electronic structure, as well as the employing this system to study atomic ensemble effects in electrocatalysis and as a template to fabricate nanostructures on surfaces. Additionally, theoretical calculations are particularly necessary in order to understand the adsorption of hydrogen on cyanidemodified Pt(111) surfaces. The present contribution addresses these points.

\section{Experimental and computational details}

Experimental details have been reported previously [11,12,15-18]. Briefly, cyanide-modified $\operatorname{Pt}(111)$ electrodes were prepared by immersion of a clean and wellordered $\mathrm{Pt}(111)$ surface in a $0.1 \mathrm{M} \mathrm{KCN}$ (Merck, p.a.) solution for approximately 3 min, after which the electrode was rinsed with ultrapure water and transferred to the electrochemical or spectroelectrochemical cell containing the cyanide-free solutions. A reversible hydrogen electrode (RHE) and a platinum wire were used as reference and counter electrode, respectively. All the potentials in the text are referred to the RHE.

Calculations were performed either with the DACAPO [20] or the SIESTA [21] DFT codes. In those cases in which the same calculation was performed with both codes, identical results, within the error margins, were obtained. More computational details can be found in the Supporting Information.

\section{Results and discussion}

Although the structure of adsorbed cyanide on $\mathrm{Pt}(111)$ electrodes has been elucidated by LEED [1] and in situ STM [4,5], and although many unique properties of these chemically-modified electrodes have been experimentally proved [6-11], there is a lack of theoretical studies concerning the structure and the configuration adopted by adsorbed cyanide on $\mathrm{Pt}(111)$ surfaces. Theoretical calculations are particularly necessary in order to understand (i) the reason why the cyanide adlayer adopts the experimentally observed $(2 \sqrt{3} \times 2 \sqrt{3}) R 30^{\circ}$ structure and (ii) the effect of adsorbed cyanide on the electronic structure of the Pt atoms not directly bonded to $\mathrm{CN}$, and the experimental results regarding the adsorption of hydrogen on cyanide-modified $\operatorname{Pt}(111)$.

3.1. Structure of cyanide adsorbed on Pt(111) surfaces. In order to study the dependence of the adsorption energy of cyanide on the coverage of $\mathrm{CN}_{\mathrm{ad}}$, we have calculated the adsorption energy of adsorbed $\mathrm{CN}$ on $\operatorname{Pt}(111)$ surfaces for different adsorption sites (on-top, bridge, fcc-hollow and hcp-hollow) and various configurations 
in the coverage interval between 0.25 and $1 \mathrm{ML}$. The adsorption energy was calculated computed the changes in the work function induced by $\mathrm{CN}_{\mathrm{ad}}$ on a $\operatorname{Pt}(111)$ surface, given by Equation 2, where the sub-index adsorbate is referred to $\mathrm{CN}_{\mathrm{ad}}$. The calculated work function of the $\operatorname{Pt}(111)$ surface obtained using DACAPO is $\Phi_{\mathrm{Pt}(111)}=5.80 \mathrm{eV}$.

$$
\begin{aligned}
& E_{\mathrm{ad}}=E_{\mathrm{CN}-\mathrm{Pt}(111)}-\left(E_{\mathrm{CN}}+E_{\mathrm{Pt}(111)}\right) \\
& \Delta \Phi=\Phi_{\text {adsorbate } \mathrm{Pt}(111)}-\Phi_{\mathrm{Pt}(111)}
\end{aligned}
$$

Figure 1 shows top views of the configurations with $\mathrm{CN}_{\mathrm{ad}}$ in an on-top position for which $E_{\mathrm{ad}}$ of cyanide on $\operatorname{Pt}(111)$ at $\theta_{\mathrm{CN}}=0.25$ (Figure $1 \mathrm{~A}$ ), $\theta_{\mathrm{CN}}=0.75$ (Figure 1B), and $\theta_{\mathrm{CN}}=1$ (Figure 1C) were calculated. Calculations for the same cyanide coverages with all the CNs in bridge, fcc-hollow or hcp-hollow sites were performed with the same structures by simply shifting the $\mathrm{CN}$ groups to the corresponding adsorption site. It must be noted that none of these theoretical structures has been observed experimentally. For the particular case of $0.5 \mathrm{ML}$, we have calculated the adsorption energy of cyanide for three different configurations: (i) the experimentally observed $(2 \sqrt{3} \times 2 \sqrt{3}) R 30^{\circ}$ structure (Figure 2A), labeled top(exp) in Table 1; (ii) a zig-zag distribution with all the CN groups adsorbed on-top (Figure 2B), that resulted after relaxation of a linear distribution of cyanide in a $2 \times 2$ unit cell, due to the repulsion between the nitrogen atoms of neighboring $\mathrm{CN}$ groups; and (iii) a mix structure in which half of the $\mathrm{CN}$ groups are adsorbed on-top and the other half are adsorbed on three-fold hollow sites (Figure 2C), that resulted after relaxation of a $2 \times 2$ unit cell in which cyanide was adsorbed in the three-fold hollow (fcc or hcp) sites. The calculated adsorption energies for on-top and fcc-hollow sites corresponding to the configurations illustrated in Figures 1 and 2 are given in Table 1 (note that the results for $\theta_{\mathrm{CN}}=0.75$, corresponding to the configuration in Figure 1B, have not been included in Table 1).

The coverage dependence of the calculated adsorption energy of cyanide adsorbed on-top and at fcc-hollow sites is shown in Figure 3A. Obviously, the adsorption energy becomes less negative as the coverage increases due to the repulsion between adsorbed $\mathrm{CN}$ groups. As can be seen in Table 1 and in Figure 3A, the energy difference between different adsorption sites is too small to explain the experimentally observed preference for adsorption on-top, that most likely is due to an additional energy gain by the interaction of the negative charge accumulated on the $\mathrm{N}$ atom of the $\mathrm{CN}$ moieties with the water dipoles at the interface, which were not included in our calculations. 
As shown in Figure 3A, the calculated adsorption energy curves for $f c c$ and on-top versus the distance from the metal surface $(\mathrm{z})$ for $\mathrm{CN}_{\mathrm{ad}}$ coverages of 0.25 and 1 . At $\theta_{\mathrm{CN}}=0.25$, the charge density initially decreases fast with the distance from the surface, and then remains more or less constant until it vanishes at distances longer than the nitrogen-surface separation. In contrast, at $\theta_{\mathrm{CN}}=1$, there is a local maximum at the location of the nitrogen atoms. This electron accumulation is large enough as to produce charge repulsion between the large electronic density of the nitrogen atoms and the electrons of the $\mathrm{Pt}(111)$ surface. Since in the case of $\mathrm{CN}$ adsorbed on-top nitrogen atoms are located farther from the surface, the repulsion is lower, and the calculated adsorption energy is slightly lower for on-top sites than for $f c c$ sites. This result suggests that the calculated adsorption energy of $\mathrm{CN}$ on $\mathrm{Pt}(111)$ results from a competition between two types of forces: a chemical force, that tends to locate $\mathrm{CN}_{\mathrm{ad}}$ on the $f c c$ site, and an electrostatic force that tends to push the $\mathrm{CN}_{\mathrm{ad}}$ further from the surface and favors adsorption on-top. The larger dipole moment induced in the case of $\mathrm{CN}$ adsorption ontop at high coverage, due to the larger charge separation (Figure 3B), will favor the solvation of $\mathrm{CN}$ by water molecules, and, as noted above, will contribute to the experimentally observed preference of the $\mathrm{CN}$ groups to be adsorbed on-top, that, as noted above, cannot be justified based exclusively on our DFT calculations.

For all the structures considered in Table 1 the changes in the work function, $\Delta \Phi_{\mathrm{CN}}$, caused by $\mathrm{CN}$ adsorption, are large (of the order of a few electron volts) and positive. In an aqueous solution, the large dipole moment of the adsorbed $\mathrm{CN}$ groups will induce a net orientation of the water dipoles in the opposite direction, which will partially cancel the surface dipole potential. To get an idea of the magnitude at which the surface dipole may be compensated by the solvent orientation, we can recall the results obtained by one of us [22], who found, for the case of sp metals, a contribution of the solvent to the potential drop across the interface between -0.2 and $-0.4 \mathrm{~V}$. These results were confirmed later using semiempirical models for the metal [23] and, in the case of $\mathrm{Ag}$, the solvent contribution was predicted to be of the order of $-0.6 \mathrm{~V}$ [24], in agreement with experimental work function measurements [25]. More recently, one of us has determined experimentally, for the case of $\operatorname{Pt}(111)$ and CO-covered $\operatorname{Pt}(111)$ electrodes in $0.1 \mathrm{M} \mathrm{HClO}_{4}$, the contribution at the pzc of the interfacial water layer to the potential drop across the interface [26], that was found to be of $-1.07 \mathrm{~V}$ in the case of $\mathrm{Pt}(111)$ and of $-0.2 \mathrm{~V}$ in the case of $\mathrm{Pt}(111)$ covered by a saturated $\mathrm{CO}$ adlayer. 
Nevertheless, in the present case, a net increase of the work function should result, values. Therefore, the adsorption of cations will set in at more positive electrode potentials than at the bare $\operatorname{Pt}(111)$ electrodes. The larger changes in the work function upon adsorption of cyanide when on-top sites are occupied at different $\mathrm{CN}$ coverages, including the $(2 \sqrt{ } 3 \times 2 \sqrt{ } 3) R 30^{\circ}$ structure observed experimentally, as compared with $\mathrm{CN}$ adsorbed on fcc-hollow sites, are also due to the larger dipole moment of $\mathrm{CN}_{\mathrm{ad}}$ in the former case.

As can be seen in Figure 2A, a pseudohexagonal arrangement of the adsorbed cyanide groups results after relaxation of the experimentally observed $(2 \sqrt{3} \times 2 \sqrt{ } 3) R 30^{\circ}$ structure of cyanide-modified $\operatorname{Pt}(111)$, due to the tendency of the nitrogen atoms to be as far from each other as possible, causing the $\mathrm{CN}$ groups not to be perpendicular to the metal surface. The adsorption energy calculated for the relaxed $(2 \sqrt{3} \times 2 \sqrt{3}) R 30^{\circ}$ structure is $-3.17 \mathrm{eV}$ (Table 1), and is very close in energy to the other two alternative configurations with the same $\theta_{\mathrm{CN}}$ (Table 1): the zig-zag distribution, shown in Figure 2B $\left(E_{\mathrm{ad}}=-3.10 \mathrm{eV}\right)$, and the mix structure (Figure $\left.2 \mathrm{C}, E_{\mathrm{ad}}=-3.23 \mathrm{eV}\right)$. The slightly higher stability of the latter structure is mainly due to the location of the $\mathrm{CN}$ groups at different heights above the metal surface (Figure 2C), which lowers the repulsion between the $\mathrm{N}$ atoms of two neighboring $\mathrm{CN}$ groups. These results indicate that, from a thermodynamical point of view, equilibrium between the three structures described above should be expected. However, as indicated above, only the $(2 \sqrt{3} \times 2 \sqrt{3})$ structure has been experimentally observed. A cation located at the center of each hexagonal cyanide ring of the $(2 \sqrt{3} \times 2 \sqrt{ } 3)$ structure, as suggested by Itaya and co-workers based on their STM images [5] in solutions containing $\mathrm{K}^{+}$or $\mathrm{Na}^{+}$, could explain the tendency of $\mathrm{CN}_{\mathrm{ad}}$ to form an ordered array of hexagons, instead of distributing themselves over the surface with a homogeneous $\mathrm{CN}-\mathrm{CN}$ separation. However, according to our DFT calculations of the adsorption energy of alkaline metal cations (approximated as neutral metals) on different adsorption sites (Table 2), the centre of the $\mathrm{CN}$ hexagonal rings (one adsorbed cation per unit cell, Figure 4A) is the most favorable site in the case of $\mathrm{K}$, but adsorption at the $(\mathrm{CN})_{3}$ sites (honeycomb structure, Figure $4 \mathrm{~B}$ ) is the most favorable in the case of $\mathrm{Na}$. In both cases, adsorption at the $(\mathrm{CN})_{4}$ sites (Figure $4 \mathrm{C}$, kagome structure) is the least favorable. (A kagome lattice is an arrangement of lines composed of interlaced triangles, such that each point where two lines cross has four neighboring similar crossing points. See, e.g, Fig. 4C and Fig. 5.) We would like to note here that, in 
the first-principles calculations method that we have used, no particular assumption is determined by the energy minimization of the energy functional with respect to the electric density. In this respect, it is interesting to point out that the cations do take, as chemical intuition dictates, a large positive charge, as can be noted in the sixth column of Table 2 .

In any case, we have strong grounds to affirm that cations, which are always present during the experimental formation of the cyanide adlayer, may play an important role in determining the structure of cyanide-modified $\operatorname{Pt}(111)$ electrodes. Experimental evidence of the presence of cations attached to the cyanide-modified Pt(111) has been reported even under UHV conditions by ex situ LEED experiments [1]. Our recent quantitative study of non-covalent interactions between alkali-metal cations and the $\mathrm{CN}$ groups of cyanide-modified $\mathrm{Pt}(111)$ electrodes has shown that a good match between the size of the cation and that of the cavity in which it has to be accommodated is critical in determining the cation's adsorption energy [17]. A comparison of the zig-zag and the mix structures with the $(2 \sqrt{3} \times 2 \sqrt{ } 3)$ structure suggests that the size of the different cavities available for the adsorption of cations plays a crucial role in determining the optimized configuration. The mix top-fcc arrangement, which is the most stable according to the theoretical calculations, does not seem a stable candidate for the adsorption of cations due to the large size of the cavity formed by a trigonal arrangement of $\mathrm{Pt}$ atoms. As for the zig-zag structure, although the cavity in this case is quite similar to that of the experimentally observed structure, in the presence of counter-ions the $\mathrm{CN}$ groups probably tend to rearrange, rendering a distribution less stable than the $(2 \sqrt{3} \times 2 \sqrt{ } 3)$ structure.

3.2. Hydrogen adsorption on cyanide-modifed Pt(111) surfaces. The double layercorrected voltammetric charge in the hydrogen adsorption region of a cyanide-modified $\operatorname{Pt}(111)$ electrode amounts to $c a .80 \mu \mathrm{C} \mathrm{cm}^{-2}$, which is the charge expected for the adsorption of atomic hydrogen on two thirds of the Pt atoms left free upon modification of the $\operatorname{Pt}(111)$ electrode with cyanide, in very good agreement with Huerta et al. [7], who suggested that adsorbed cyanide blocks only some of the sites available for hydrogen adsorption. Interestingly, on cyanide-modified $\mathrm{Pt}(111)$ the onset of hydrogen adsorption is shifted positively by $c a$. $0.20 \mathrm{~V}$ with respect to unmodified $\operatorname{Pt}(111)$ electrodes (Figure S1). This implies that $\Delta G_{0}$ of $\mathrm{H}_{\text {upd }}\left(\theta_{H}=0\right)$ is $c a .19 \mathrm{~kJ} \mathrm{~mol}^{-1}$ more 
negative on cyanide-modified $\operatorname{Pt}(111)$ [12], and might suggest a modification of the will show below, this is not the case. Actually, the onset of hydrogen evolution does not seem to be affected by the presence of $\mathrm{CN}_{\mathrm{ad}}$ on cyanide-modified $\mathrm{Pt}(111)$ electrodes (Figure S1), onto which on-top sites, thought to be the active ones in the evolution of $\mathrm{H}_{2}$ on $\operatorname{Pt}(111)$ electrodes, are perfectly available. If these sites remain electronically unaltered, hydrogen evolution would be expected to coincide on both $\operatorname{Pt}(111)$ and cyanide-modified $\operatorname{Pt}(111)$ electrodes.

The shift in the onset of hydrogen adsorption can be explained by the formation in the $\mathrm{H}_{\text {upd }}$ region of adsorbed hydrogen isocyanide, $\mathrm{CNH}_{\mathrm{ad}}$, instead of $\mathrm{H}_{\mathrm{ad}}$ directly bonded to the Pt atoms. This idea had been already proposed by Schardt et al. [27], who suggested that the $\mathrm{CNH}_{\mathrm{ad}}$ adlayer behaves as a polyprotic acid. The formation of $\left(\mathrm{CN}_{\mathrm{ad}}\right)_{\mathrm{x}}-\mathrm{H}$ (with $\mathrm{x}$ decreasing with decreasing potential within the $\mathrm{H}$ adsorption region) would explain all the previous experimental facts. As can be observed in Figure 5, the charge density at the broad peak at $0.48 \mathrm{~V}$ in the $\mathrm{H}_{\text {upd }}$ region is $c a .20 \mu \mathrm{C} \mathrm{cm}^{-2}\left(\theta_{\mathrm{CNH}}=\right.$ $1 / 12 \mathrm{ML})$, which might correspond to a $\left(\mathrm{CN}_{\mathrm{ad}}\right)_{6}-\mathrm{H}$ stoichiometry. The minimum of current density at $c a .0 .40 \mathrm{~V}$ corresponds to a charge density of about $32 \mu \mathrm{C} \mathrm{cm}^{-2}\left(\theta_{\mathrm{CNH}}\right.$ $=1 / 8 \mathrm{ML})$, coinciding with the charge expected for the formation of $\left(\mathrm{CN}_{\mathrm{ad}}\right)_{4}-\mathrm{H}$. Finally, at $0.37 \mathrm{~V}$ and $c a .0 .20 \mathrm{~V}$, the charge densities are $40 \mu \mathrm{C} \mathrm{cm}^{-2}\left(\theta_{\mathrm{CNH}}=1 / 6 \mathrm{ML}\right)$ and $64 \mu \mathrm{C} \mathrm{cm}^{-2}\left(\theta_{\mathrm{CNH}}=0.25 \mathrm{ML}\right)$, respectively. The former may correspond to a $\left(\mathrm{CN}_{\mathrm{ad}}\right)_{3}-\mathrm{H}$ stoichiometry (honeycomb structure), and the latter to a $\left(\mathrm{CN}_{\mathrm{ad}}\right)_{2}-\mathrm{H}$ stoichiometry (kagome structure).

Itaya and co-workers [5] attributed the STM images of a cyanide-modifed $\operatorname{Pt}(111)$ electrode obtained at $0.30 \mathrm{~V}$ vs. RHE (well within the $\mathrm{H}_{\text {upd }}$ region) in perchloric acid solutions to a $(\sqrt{ } 7 \times \sqrt{ } 7) R 19^{\circ}$ structure, but this is in contradiction with the absence in the cyclic voltammogram of any feature indicating a phase transition, as would be expected for a change from a long-range ordered $(2 \sqrt{3} \times 2 \sqrt{3}) R 30^{\circ}$ structure to a longrange ordered $(\sqrt{ } 7 \times \sqrt{ } 7) R 19^{\circ}$ structure. As shown in Figure 5 , the structure found by Itaya and co-workers can also be interpreted as a kagome structure, in excellent agreement with our analysis above, based on the charge density measured in the corresponding $\mathrm{CV}$.

The IR spectra of cyanide adsorbed on $\operatorname{Pt}(111)$ electrodes have been intensively studied both in acidic [6,7] and in alkaline solutions [3,4,28,29]. The spectra show a single vibrational band corresponding to the stretching vibration of a $\mathrm{CN}$ group 
adsorbed on-top of a platinum atom through its carbon atom [3,4,6,7]. A plot of the $\mathrm{CN}_{\mathrm{L}}$ stretching frequency of cyanide-modified $\mathrm{Pt}(111)$ vs. the electrode potential (Figure S2) shows two clearly different slopes: at $\mathrm{E} \leq 0.5 \mathrm{~V}$ the $\mathrm{CN}_{\mathrm{L}}$ stretching frequency increases with potential with a slope of $82 \mathrm{~cm}^{-1} \mathrm{~V}^{-1}$, this being significantly smaller than that of ca. $100 \mathrm{~cm}^{-1} \mathrm{~V}^{-1}$ reported by Huerta et al. [6,7], while for $E \geq 0.60 \mathrm{~V}$ the slope is $25 \mathrm{~cm}^{-}$ ${ }^{1} \mathrm{~V}^{-1}$, in good agreement with the literature [6,7]. Some authors attributed this change in the Stark tuning rate to a change from N-bound $\mathrm{CN}$ at $E \leq 0.50 \mathrm{~V}$ to C-bound $\mathrm{CN}$ at $E>$ $0.50 \mathrm{~V}[6,7,30]$, and this assignment was supported by theoretical calculations of $\mathrm{Pt}-\mathrm{CN}^{-}$ and $\mathrm{Pt}^{-\mathrm{NC}^{-}}$vibrational systems [31,32]. In contrast, Paulissen and Korzeniewski [2] suggested that the changes in the Stark tuning rate correspond to the conversion from Pt-CN to Pt-CNH species. Naturally, due to bond order conservation, the adsorption of hydrogen on the nitrogen atoms of adsorbed cyanide should weaken the carbon-nitrogen bond, and hence decrease the corresponding C-N stretching vibrational frequency. A comparison of the plot of the $\mathrm{CN}_{\mathrm{L}}$ stretching frequency of cyanide-modified $\mathrm{Pt}(111) \mathrm{vs}$. the electrode potential (Figure S2) with the CV of the cyanide-modified $\operatorname{Pt}(111)$ electrode (Figure S1) strongly suggests that the high slope at $E \leq 0.50 \mathrm{~V}$ must be due to the presence of hydrogen protonating the nitrogen atoms of the adsorbed cyanide. Therefore, our hypothesis is that over the whole frequency range between 2085 and $2123 \mathrm{~cm}^{-1}$ the band of the cyanide-modified $\mathrm{Pt}(111)$ corresponds to C-bound $\mathrm{CN}$ adsorbed on-top on $\mathrm{Pt}(111)$ and that the change in the Stark tuning rate of the $\mathrm{CN}$ stretching frequency at ca. $0.50 \mathrm{~V}$, coinciding with the onset of hydrogen adsorption in the cyclic voltammogram, can be explained by the formation of $\left(\mathrm{CN}_{\mathrm{ad}}\right)_{\mathrm{x}}-\mathrm{H}$.

We have analyzed the projected density of states (PDOS) of the topmost $\mathrm{Pt}$ atoms, in order to identify the electronic factors that control the adsorption of $\mathrm{CN}$ on $\operatorname{Pt}(111)$ surfaces, and in order to prove our assumption that the electronic structure of the surface Pt atoms that are not directly bonded to $\mathrm{CN}$ remains essentially unaltered. Figure $6 \mathrm{~A}$ shows the DOS projected on the carbon atom of a $\mathrm{CN}_{\mathrm{ad}}$ and on the $\mathrm{Pt}$ atom of the cyanide-modified $\operatorname{Pt}(111)$ surface bonded to it. As can be observed there is a resonance of $\mathrm{Pt} / \mathrm{CN}$ states at around $-16 \mathrm{eV}$, where the $2 \mathrm{sp}$ states of carbon and the $6 \mathrm{sp}$ states of platinum clearly overlap. A contribution of the $\mathrm{d}$ states of $\mathrm{Pt}$ can also be detected at around $-7.5 \mathrm{eV}$.

The DOS projected on the $d$-band of the surface Pt atoms of a cyanide-modified $\operatorname{Pt}(111)$ electrode with the $(2 \sqrt{3} \times 2 \sqrt{3}) \mathrm{R} 30^{\circ}$ structure (Figure $\left.6 \mathrm{~B}\right)$, shows that the PDOS 
of the Pt atoms directly bonded to the $\mathrm{CN}_{\mathrm{ad}}$ is shifted to lower energies as compared to

The adsorption energy of $\mathrm{CNH}$ on $\mathrm{Pt}(111)$ is calculated according to Eq. 6:

$$
E_{a d}=E_{C N H-P_{t}(111)}-\left(E_{C N H}+E_{P_{t}(111)}\right)
$$

The $\mathrm{CN}$ adsorption energies in Table 4 are consistent with those shown in Table 1, although the latter were calculated with DACAPO and the former with SIESTA. Interestingly, the energy of adsorption of hydrogen on the free $\mathrm{Pt}$ atoms of a $\mathrm{Pt}(111)$ surface with a low coverage of $\mathrm{CN}$ (Table 4, Figure 7C) is similar to that on the different sites of a clean $\operatorname{Pt}(111)$ surface (Table 3, Figure 7A), and nearly half the energy corresponding to the protonation of the nitrogen atom of $\mathrm{Pt}(111)-\mathrm{CN}$ to form $\mathrm{Pt}(111)-\mathrm{CNH}$ (Table 4, Figure 7B). This is in agreement with the result of the PDOS in Figure 6 and with our hypothesis that the shift of $0.2 \mathrm{~V}$ in the onset of hydrogen 
adsorption on cyanide-modified $\operatorname{Pt}(111)$, as compared to clean $\operatorname{Pt}(111)$, is due to the formation of $\mathrm{CNH}_{\mathrm{ad}}$.

We have also studied the adsorption energy of $\mathrm{CNH}$ on $\mathrm{Pt}(111)$, given by Equation 6, at different coverages, and have compared it with the adsorption energy of $\mathrm{CN}$ on $\mathrm{Pt}(111)$, given by Equation 1. We have also computed the changes in the work function induced by $\mathrm{CNH}_{\mathrm{ad}}$ on a $\mathrm{Pt}(111)$ surface using Equation 2, where the sub-index adsorbate is now referred to $\mathrm{CNH}_{\mathrm{ad}}$. The results of these calculations are shown in Table 5.

The value for the adsorption energy of $0.25 \mathrm{ML}$ of $\mathrm{CNH}$ on $\mathrm{Pt}(111)$ in Table 5 is in very good agreement with the value obtained for $0.19 \mathrm{ML}$ of $\mathrm{CNH}$ in Table 4, although the former was obtained with DACAPO and the latter with SIESTA. Table 5 shows that the adsorption of $\mathrm{CNH}_{\mathrm{ad}}$ inverts the dipole moment of the surface with respect to $\mathrm{CN}_{\mathrm{ad}}$ (Table 1). As happens with $\mathrm{CN}_{\mathrm{ad}}$, large differences in the work function changes are found for $\mathrm{CNH}_{\mathrm{ad}}$ in the different configurations studied, in contrast with the small change in the adsorption energy found for the same coverages of $\mathrm{CNH}_{\mathrm{ad}}$ (Table 5). The positive values calculated for $\Delta \Phi_{(\mathrm{CNH})}$ using DACAPO (Table 5) are in agreement with the positive total charge on the $\mathrm{CNH}_{\mathrm{ad}}$ species inferred from the Mulliken analysis, obtained using SIESTA, in Table 4.

The adsorption energy of hydrogen on $\operatorname{Pt}(111)$ covered by $\mathrm{CN}$ with $\theta_{\mathrm{CN}}=0.25$ (Figures 8A, 8B, 9A and 9B) and $\theta_{\mathrm{CN}}=0.5$ (Figures 8C, 8D, 9C and 9D), both on the nitrogen atom of adsorbed cyanide (Figure 8) and on the Pt atoms of the Pt(111) surface (Figure 9), was also calculated according to Equations 5 and 7. The results are summarized in Table 6. Although the zig-zag arrangement is one of the most stable configurations for $0.5 \mathrm{ML}$ of $\mathrm{CN}$ on $\mathrm{Pt}(111)$, as can be observed in Table 1, for $\mathrm{CNH}_{\mathrm{ad}}$ it becomes unfavourable, because the $\mathrm{CNH}$ groups rearrange in a linear configuration in order to favour the formation of hydrogen bonds between neighbouring adsorbates (Figures $8 \mathrm{C}$ and D), that add additional stability to the adlayer and cannot be formed in the zig-zag configuration. It must be noted that the values of $E_{\mathrm{ads}}^{\mathrm{H}-\mathrm{Pt}}$ shown in Table 6 and calculated with Eq. 7 correspond to the adsorption of $\mathrm{H}$ on the free Pt atoms of $\mathrm{Pt}(111)-\mathrm{CNH}_{\mathrm{ad}}$, when hydrogen is already adsorbed on the nitrogen atom of the $\mathrm{CN}$ groups. We have checked that the difference of these results with respect to $E_{\mathrm{ad}}^{\mathrm{H}-\mathrm{Pt}}$ on $\operatorname{Pt}(111)-\mathrm{CN}_{\mathrm{ad}}$, i.e., when $\mathrm{H}$ is not bonded to the nitrogen atom of the $\mathrm{CN}$ groups, is negligible (lower than $0.1 \mathrm{eV}$ ). This is confirmed by the similitude between the energy 
of adsorption of $\mathrm{H}$ on a free Pt atom in Table 4 and in Table 6, although in the former despite the differences in $\theta_{\mathrm{CN}}$ and $\theta_{\mathrm{H}}$.

$$
E_{\mathrm{ad}}^{\mathrm{H}-\mathrm{Pt}}=E_{\mathrm{HNC}-\mathrm{HPt}(111)}-\left(\frac{E_{\mathrm{H}_{2}}}{2}+E_{\mathrm{HNC}-\mathrm{Pr}(111)}\right)
$$

Although none of the structures for which $E_{\text {ad }}^{\mathrm{H}-\mathrm{Pt}}$ was calculated in Table 6 corresponds to the experimentally observed $(2 \sqrt{3} \times 2 \sqrt{3})$ structure, the results corroborate that the adsorption of hydrogen on the free Pt atoms of the different structures of cyanide-modified $\operatorname{Pt}(111)$ is very close in energy to the adsorption on unmodified $\mathrm{Pt}(111)$, as already deduced from the results of the calculation of the $d$-band PDOS (Figure 6) and from the results in Table 4. These results show that hydrogen adsorbed on the nitrogen atom of $\mathrm{CN}_{\mathrm{ad}}$ is between ca. 0.5 and ca. $1 \mathrm{eV}$ more stable than hydrogen adsorbed on the free $\mathrm{Pt}$ atoms of the cyanide-modified $\mathrm{Pt}(111)$ surface, and strongly support the hypothesis that the hydrogen adsorption region on cyanidemodified $\operatorname{Pt}(111)$ is due to the formation of $\left(\mathrm{CN}_{\mathrm{ad}}\right)_{\mathrm{x}}-\mathrm{H}$.

In addition to the calculations above, that involve surface structures not observed experimentally, the adsorption of $\mathrm{H}$ onto the experimentally observed Pt-CN $(2 \sqrt{3} \mathrm{x}$ $2 \sqrt{3}) R 30^{\circ}$ surface was also investigated, both in the presence and in the absence of a competing species such as $\mathrm{K}$. The adsorption of $\mathrm{H}$ onto the free $\mathrm{Pt}$ atoms of a Pt-CN $(2 \sqrt{3} \times 2 \sqrt{ } 3) R 30^{\circ}$ surface was studied at a low coverage $(\theta=1 / 12)$ of $\mathrm{H}$, because the onset of hydrogen adsorption, for which a positive shift of $0.20 \mathrm{~V}$ is observed in the case of cyanide-modified $\operatorname{Pt}(111)$, corresponds to the limit of zero coverage. The different possible adsorption modes that were assessed include $\mathrm{H}$ on top of the free $\mathrm{Pt}$ atoms considering the three different possible sites: (i) $\mathbf{P t}-(\mathbf{C N})_{3}$, a free $\mathrm{Pt}$ with 3 first neighbors with a $\mathrm{CN}_{\mathrm{ad}}$ (Figure 10A); (ii) Pt-(CN) $)_{4}$, a free Pt with 4 first neighbors with a $\mathrm{CN}_{\mathrm{ad}}$ (Figure 10B); and (iii) Pt-(CN) $)_{6}$, a free Pt with 6 first neighbors with a $\mathrm{CN}_{\mathrm{ad}}$ (Figure 10C). We also tried to adsorb $\mathrm{H}$ on hollow sites. On the Pt-CN $(2 \sqrt{3} \times 2 \sqrt{3}) R 30^{\circ}$ surface there are no hollow sites surrounded by three free Pt atoms, but it contains hollow sites composed of either 2 free Pt and $1 \mathrm{Pt}-\mathrm{CN}_{\mathrm{ad}}$ or 1 free Pt and $2 \mathrm{Pt}-\mathrm{CN}_{\mathrm{ad}}$. When an $\mathrm{H}$ atom was placed on one of these hollow sites, we observed two different behaviors: the $\mathrm{H}$ atom left the surface, and it either protonated a $\mathrm{N}$ atom or a $\mathrm{C}$ atom. In the latter case, the resulting $\mathrm{HCN}$ molecule desorbed from the surface. 
We also studied $\mathrm{H}$ adsorption at the $\mathrm{N}$ atoms of the $\mathrm{CN}_{\mathrm{ad}}$ of a Pt-CN $(2 \sqrt{3} \mathrm{x}$ $2 \sqrt{ } 3) R 30^{\circ}$ surface, varying the $\mathrm{H}$ coverage between $1 / 12$ (Pt-CN-Hx1, Figure 10D) and $1 / 4$ (with respect to the surface Pt atoms). For $\theta=1 / 4$, two different stable structures were found, which we have called Pt-CN-Hx3 geom-1 (Figure 10E) and Pt-CN-Hx3 geom-2 (Figure 10F). Finally, $\mathrm{H}$ adsorption on top of the free $\mathrm{Pt}$ atoms was also examined in the presence of non-covalently attached $\mathrm{K}$ forming a honeycomb adlayer [17], and in the presence of a non-covalently attached $\mathrm{K}$ adlayer with the centre of the ring structure. The results of these calculations are summarized in Table 7.

Interestingly, protonation of the $\mathrm{N}$ atoms of the adsorbed $\mathrm{CNs}$ of the $(2 \sqrt{3} \mathrm{x}$ $2 \sqrt{ } 3) R 30^{\circ}$ structure is energetically very favorable, with an adsorption energy more than $1 \mathrm{eV}$ larger than $\mathrm{H}$ bonded to the $\mathrm{CN}$-free $\mathrm{Pt}$ atoms, which is barely affected by the presence of $\mathrm{K}$ and whose adsorption energy (Table 7) is roughly the same as on clean $\mathrm{Pt}(111)$ (Table 3). Formation of $\left(\mathrm{CN}_{\mathrm{ad}}\right)_{\mathrm{x}}-\mathrm{H}$ explains, hence, the experimentally observed $0.2 \mathrm{~V}$ positive shift of the onset of hydrogen adsorption. Our calculations also confirm that the effect of the alkaline cations on the CV of a cyanide modified $\mathrm{Pt}(111)$ electrode can be explained by a competition for the same adsorption sites, as we have suggested recently [17].

Finally, as illustrated in Figure 11 and as suggested by the high value of the hydrogen adsorption energy of the Pt-CN-Hx1 structure (Figure 10D and Table 2), the formation of $\left(\mathrm{CN}_{\mathrm{ad}}\right)_{\mathrm{x}}-\mathrm{H}$ is probably further stabilized by the formation of hydrogenbonds between nitrogen atoms of neighboring cyanide groups in the hexagonal ring, as happens with the linear configuration (Figures 8C and D).

Our theoretical calculations show that hydrogen adsorption on top of the free $\mathrm{Pt}$ atoms of the $\mathrm{CN}_{\mathrm{ad}}$-covered $\operatorname{Pt}(111)$ surface is also thermodynamically stable for all the configurations analyzed (Tables and 4, 6 and 7). This supports the idea that, in the potential region between $0.6 \mathrm{~V}$ and $0.1 \mathrm{~V}$, hydrogen adsorbs on the nitrogen atoms of the cyanide groups, but, at sufficiently negative potentials, and once all the available $\mathrm{CN}_{\mathrm{ad}}$ sites have been occupied, hydrogen can also adsorb directly on the metal, and probably acts as the intermediate species in $\mathrm{H}_{2}$ evolution.

\section{Conclusions}

DFT calculations cannot explain by themselves the preference for the experimentally observed structure adopted by cyanide on $\operatorname{Pt}(111)$ electrodes, suggesting that adsorption of cyanide forming a $(2 \sqrt{3} \times 2 \sqrt{3}) R 30^{\circ}$ structure is driven by the 
presence of cations, other structures isoenergetic with it presenting cavities with sizes or geometries inappropriate for hosting the cations.

DFT calculations of the DOS projected onto those Pt atoms that are not directly bonded to $\mathrm{CN}$ show that the electronic structure of these atoms remains essentially unaltered, which demonstrates that $\mathrm{CN}_{\mathrm{ad}}$ acts as an inert site blocker. For this reason, cyanide-modified $\mathrm{Pt}(111)$ electrodes are unique for studying atomic ensemble effects in electrocatalysis using the site-knockout strategy.

According to DFT calculations, protonation of the nitrogen atoms of $\mathrm{CN}_{\mathrm{ad}}$ on $\mathrm{Pt}(111)$ is clearly favored over adsorption on a Pt atom. The positive shift in the onset of hydrogen adsorption in the $\mathrm{CV}$ of cyanide-modified $\mathrm{Pt}(111)$ electrodes can, hence, be qualitatively explained by the formation of $\left(\mathrm{CN}_{\mathrm{ad}}\right)_{\mathrm{x}}-\mathrm{H}$, instead of $\mathrm{H}$ bonded to the $\mathrm{Pt}$ atoms that remain free in the $(2 \sqrt{3} \times 2 \sqrt{3}) R 30^{\circ}$ cyanide-modified $\operatorname{Pt}(111)$ structure. An analysis of the FTIR spectra shows that the Stark tuning rate of the CN stretching frequency of cyanide-modified $\operatorname{Pt}(111)$ changes at a potential coinciding with the onset of hydrogen adsorption in the corresponding $\mathrm{CV}$, which can also be explained by the formation of $\left(\mathrm{CN}_{\mathrm{ad}}\right)_{\mathrm{x}}-\mathrm{H}$.

\section{Acknowledgements}

A.C. acknowledges the support of the DGI (Spanish Ministry of Science and Innovation) through Project CTQ2009-07017. W.S acknowledges financial support by the Deutsche Forschungsgemeinschaft under Schm 344/40-1, Schm 344/34-1.2 and FOR 1376. W.S. and P.Q. thank DFG-CONICET International Cooperation and CONICET for continued support. E.P.M.L. and M.Z.-M. wish to acknowledge CONICET PIP: 112-200801-000983, Secyt UNC, Program BID (PICT 2006 N 946), and PME: 2006-01581 for financial support. P.Q. acknowledges PICT 0737-2008. A generous grant of computing time from the Baden-Wuerttemberg grid is gratefully acknowledged. M.E.-E. acknowledges an FPI fellowship from the Spanish Ministry of Science and Innovation and an accommodation grant at the Residencia de Estudiantes from the Madrid City Council.

\section{References}

[1] J.L. Stickney, S.D. Rosasco, G.N. Salaita, A.T. Hubbard, Langmuir 1 (1985) 66.

[2] V.B. Paulissen, C. Korzeniewski, J. Phys. Chem. 96 (1992) 4563.

[3] C.S. Kim, C. Korzeniewski, J. Phys. Chem. 97 (1993) 9784.

[4] C. Stuhlmann, Surf. Sci. 335 (1995) 221.

[5] Y.-G. Kim, S.-L. Yau, K. Itaya, J. Am. Chem. Soc. 118 (1996) 393. 
[6] F. Huerta, E. Morallón, C. Quijada, J.L. Vázquez, A. Aldaz, Electrochim. Acta 44 (1998) 943.

[7] F.J. Huerta, E. Morallón, J. Vazquez, A. Aldaz, Surf. Sci. 396 (1998) 400.

[8] F. Huerta, E. Morallón, C. Quijada, J.L. Vázquez, L.E.A. Berlouis, J. Electroanal. Chem. 463 (1999) 109.

[9] F. Huerta, E. Morallón, J.L. Vázquez, Surf. Sci. 431 (1999) L577.

[10] F. Huerta, E. Morallón, J.L. Vázquez, Electrochem. Commun. 4 (2002) 251.

[11] I. Morales-Moreno, A. Cuesta, C. Gutiérrez, J. Electroanal. Chem. 560 (2003) 135.

[12] A. Cuesta, M. Escudero, Phys. Chem. Chem. Phys. 10 (2008) 3628.

[13] A. Cuesta, ChemPhysChem 12 (2011) 2375.

[14] D. Strmcnik, M. Escudero-Escribano, K. Kodama, V.R. Stamenkovic, A. Cuesta, N.M. Markovic, Nature Chem. 2 (2010) 880.

[15] A. Cuesta, J. Am. Chem. Soc. 128 (2006) 13332.

[16] A. Cuesta, M. Escudero, B. Lanova, H. Baltruschat, Langmuir 25 (2009) 6500.

[17] M. Escudero-Escribano, M.E. Zoloff Michoff, E.P.M. Leiva, N.M. Marković, C. Gutiérrez, Á. Cuesta, ChemPhysChem 12 (2011) 2230.

[18] M. Escudero, J.F. Marco, A. Cuesta, J. Phys. Chem. C 113 (2009) 12340.

[19] M. Escudero-Escribano, PhD Thesis, Universidad Autónoma de Madrid, 2011, http://hdl.handle.net/10261/42378.

[20] B. Hammer, L.B. Hansen, J.K. Nørskov, Phys. Rev. B 59 (1999) 7413.

[21] J.M. Soler, E. Artacho, J.D. Gale, A. García, J. Junquera, P. Ordejón, D. SánchezPortal, J. Phys. Condens. Matter. 14 (2002) 2745.

[22] W. Schmickler, Chem. Phys. Lett. 99 (1983) 135.

[23] M.I. Rojas, E.P.M. Leiva, J. Electroanal. Chem. 303 (1991) 55.

[24] M.I. Rojas, E.P.M. Leiva, Surf. Sci. 227 (1990) L121.

[25] K. Bange, T.E. Madey, J.K. Sass, E.M. Stuve, Surf. Sci. 183 (1987) 334.

[26] A. Cuesta, Surf. Sci. 572 (2004) 11.

[27] B.C. Schardt, J.L. Stickney, D.A. Stern, D.G. Frank, J.Y. Katekaru, S.D. Rosasco, G.N. Salaita, M.P. Soriaga, A.T. Hubbard, Inorg. Chem. 24 (1985) 1419.

[28] W. Daum, K.A. Friedrich, C. Klünker, D. Knabben, U. Stimming, H. Ibach, Appl. Phys. A 59 (1994) 553.

[29] K.A. Friedrich, W. Daum, C. Klünker, D. Knabben, U. Stimming, H. Ibach, Surf. Sci. 335 (1995) 315.

[30] F. Huerta, F. Montilla, E. Morallón, J.L. Vázquez, Surf. Sci. 600 (2006) 1221.

[31] A. Tadjeddine, A. Peremans, A. Le Rille, W.Q. Zheng, M. Tadjeddine, J.-P. Flament, J. Chem. Soc. Faraday Trans. 92 (1996) 3823.

[32] M. Tadjeddine, J.P. Flament, Chem. Phys. 240 (1999) 39.

Figure 1. Top views of the different structures with $\theta_{\mathrm{CN}}=0.25(\mathrm{~A}), \theta_{\mathrm{CN}}=0.75(\mathrm{~B})$, and $\theta_{\mathrm{CN}}=1(\mathrm{C})$ for which the adsorption energy of cyanide adsorbed on-top on $\mathrm{Pt}(111)$ has been calculated.

Figure 2. Top and side views of the structures with $\theta_{\mathrm{CN}}=0.5$ for which the adsorption energy of cyanide on $\mathrm{Pt}(111)$ has been calculated: (A) Experimentally observed $(2 \sqrt{3} \times 2 \sqrt{ } 3) R 30^{\circ}$ structure; (B) $(2 \times 2)$ zig-zag structure; (C) $(2 \times 2)$ mix structure.

Figure 3. A) Adsorption energy of $\mathrm{CN}_{\mathrm{ad}}$ on $\mathrm{Pt}(111)$ at different coverages from 0.25 to $1 \mathrm{ML}$, with all the CNs occupying either fcc-hollow sites (black stars) or on-top sites (red circles) and adopting the structures shown in Figure 1. B) Total electronic density $\left(\rho_{\mathrm{e}}\right)$ as a function of the distance $(z)$ from the metal surface for cyanide-modified $\operatorname{Pt}(111)$. The Pt surface corresponds to $z=0$. The total charge density for adlayers with 
all the CNs at fcc-hollow and at on-top sites are compared for $\theta_{\mathrm{CN}}=0.25$ (top) and $\theta_{\mathrm{CN}}=1$ (bottom).

Figure 4. Top view of the three possible cavity sites at which cations can adsorb on the experimentally observed $(2 \sqrt{3} \times 2 \sqrt{3}) \mathrm{R} 30^{\circ}$ structure of cyanide-modified $\mathrm{Pt}(111)$ surfaces: A) $\left.\left(\mathrm{CN}_{\mathrm{ad}}\right)_{6}, \mathrm{~B}\right)\left(\mathrm{CN}_{\mathrm{ad}}\right)_{3}$ and $\left.\mathrm{C}\right)\left(\mathrm{CN}_{\mathrm{ad}}\right)_{4}$ cavities.

Figure 5. Left: Cyclic voltammogram at $50 \mathrm{mV} \mathrm{s}^{-1}$ of $\mathrm{CN}$-modified $\mathrm{Pt}(111)$ in $0.1 \mathrm{M}$ $\mathrm{HClO}_{4}$. Right: $5 \times 5 \mathrm{~nm}^{2} \mathrm{STM}$ image obtained at $0.3 \mathrm{~V}$, reprinted and adapted with permission from reference [9], copyright 1996 American Chemical Society. The image can be interpreted as a kagome structure corresponding to a $\left(\mathrm{CN}_{\mathrm{ad}}\right)_{2}-\mathrm{H}$ stoichiometry.

Figure 6. A) DOS projected on the $C$ atom of a $C_{\text {ads }}$ group of the $(2 \sqrt{3} \times 2 \sqrt{3}) \mathrm{R} 30^{\circ}$ structure and on the Pt atom bonded to it. The sp states of carbon are contrasted with, from top to bottom, the $\mathrm{s}, \mathrm{p}$, and d valence states of the metal. B) DOS of the $\mathrm{d}$ band projected on the surface atoms of a clean $\mathrm{Pt}(111)$ and of a cyanide-modified $\mathrm{Pt}(111)$ surface with the experimentally observed $(2 \sqrt{3} \times 2 \sqrt{3}) \mathrm{R} 30^{\circ}$ structure. For the cyanidemodified $\mathrm{Pt}(111)$ surface, $\mathrm{Pt}$ free atoms (not bonded to adsorbed cyanide) are distinguished from the $\mathrm{Pt}$ atoms directly bonded to $\mathrm{CN}$ (Pt occupied).

Figure 7: A) $\mathrm{H}$ adsorbed on a hollow $f c c$ site on $\mathrm{Pt}(111)$. B) $\mathrm{CN}$ adsorbed on top protonated on the $\mathrm{N}$ atom. $\mathrm{C}$ ) $\mathrm{CN}$ adsorbed on top and $\mathrm{H}$ adsorbed at a site intermediate between bridge and hcp-hollow, resulting from the relaxation of a structure in which $\mathrm{H}$ was originally adsorbed at one of the fcc-hollow sites adjacent to the adsorbed $\mathrm{CN}$ group.

Figure 8. Top view of the different configurations for which the adsorption energy of hydrogen on the nitrogen atoms of $\mathrm{CN}_{\mathrm{ad}}$ of $\mathrm{CN}-\mathrm{Pt}(111)$ surfaces has been calculated.

Figure 9. Top view of the different configurations for which the adsorption energy of hydrogen on the free Pt atoms of CNH-Pt(111) surfaces has been calculated.

Figure 10: Hydrogen adsorption on the experimentally observed $(2 \sqrt{3} \times 2 \sqrt{3}) \mathrm{R} 30^{\circ}$ structure of cyanide-modified $\mathrm{Pt}(111)$ surfaces. A) $\mathrm{Pt}-(\mathrm{CN})_{3}-\mathrm{H}, \mathrm{H}_{\text {upd }}$ on top of free $\mathrm{Pt}$ with 3 first neighbors Pt-CN $\mathrm{Cd}_{\mathrm{ad}}$. B) Pt- $(\mathrm{CN})_{4}-\mathrm{H}, \mathrm{H}_{\text {upd }}$ on top of free Pt with 4 first neighbors Pt-CN $\mathrm{Cd}_{\text {ad }}$ C) Pt- $(\mathrm{CN})_{6}-\mathrm{H}, \mathrm{H}_{\text {upd }}$ on top of free Pt with 6 first neighbors Pt- $\mathrm{CN}_{\mathrm{ad}}$. D) Pt-CN-Hx1, H protonating the $\mathrm{N}$ atom of the $\mathrm{CN}$ adlayer with $\theta=1 / 12$. E) Pt-CN$\mathrm{Hx} 3$ geom-1, $\mathrm{H}$ protonating the $\mathrm{N}$ atom of the $\mathrm{CN}$ adlayer with $\theta=1 / 4$. The red hexagon indicates the $\mathrm{CN}$ ring, that has deformed as one $\mathrm{CN}_{\mathrm{ad}}$ has shifted from an ontop to a bridge position. F) $\mathrm{Pt}-\mathrm{CNHx} 3$ geom-2, $\mathrm{H}$ protonating the $\mathrm{N}$ atom of the $\mathrm{CN}$ adlayer with $\theta=1 / 4$. G) $\mathrm{Pt}-\mathrm{CN}-\mathrm{K}($ centre $)-\mathrm{H}\left(\mathrm{CN}_{4}\right), \mathrm{H}_{\text {upd }}$ on a free $\mathrm{Pt}$ at a $\mathrm{Pt}-\mathrm{CN}_{4}$ site in the presence of a $\mathrm{K}$ adlayer with the cation located at centre of the $\mathrm{CN}$ ring. $\mathrm{H}$ ) Pt-CN$\mathrm{K}($ honeycomb $)-\mathrm{H}\left(\mathrm{CN}_{6}\right), \mathrm{H}_{\text {upd }}$ on a free $\mathrm{Pt}$ at a $\mathrm{Pt}-\mathrm{CN}_{6}$ site in the presence of a $\mathrm{K}$ honeycomb adlayer and I) Pt-CN-K(honeycomb $)-\mathrm{H}\left(\mathrm{CN}_{4}\right), \mathrm{H}_{\text {upd }}$ on a free Pt at a Pt-CN site in the presence of a $\mathrm{K}$ honeycomb adlayer.

Figure 11. Top view of a fully protonated $(2 \sqrt{3} \times 2 \sqrt{3}) \mathrm{R} 30^{\circ}$ cyanide-modified $\operatorname{Pt}(111)$ surfaces. 
Table 1. Adsorption energy $\left(E_{\text {ads }}\right)$ and work function difference $(\Delta \Phi)$ in $\mathrm{eV}$ for different configurations and coverages of the $\mathrm{CN}$ adlayer on $\mathrm{Pt}(111)$ surfaces.

\begin{tabular}{cccc}
\hline$\theta_{\text {adsorbate }}$ & Adsorption site & $E_{\text {ads }(\mathrm{CN})} / e V$ & $\Delta \Phi_{(\mathrm{CN})} / e V$ \\
\hline 0.25 & top & -3.39 & 2.75 \\
0.25 & $f c c$ & -3.47 & 1.67 \\
\hline 0.50 & top (exp.) & -3.17 & 3.56 \\
0.50 & top (zig-zag) & -3.10 & 3.48 \\
0.50 & top (linear) & -3.02 & 3.48 \\
0.50 & $f c c$ (linear) & -3.04 & 2.09 \\
0.50 & top-fcc (mix) & -3.23 & 3.24 \\
1 & top & -2.51 & 3.82 \\
\hline & $f c c$ & -2.23 & 3.33 \\
\hline
\end{tabular}


Table 2. Adsorption energies, relevant structural parameters, and Mulliken charge analysis for the three possible structures for $\mathrm{Na}+$ and $\mathrm{K}+$ adsorbed on the $\mathrm{CN}$-modified Pt(111) surface.

\begin{tabular}{|c|c|c|c|c|c|c|}
\hline Structure & $E_{\mathrm{ad}} / \mathrm{eV}$ & $d\left(\mathbf{M}_{[\mathrm{b}]}^{+}-\mathbf{P t}\right) / \mathrm{nm}$ & $d\left(\mathbf{N}-\mathbf{M}_{[\mathrm{c}]}^{+}\right) / \mathrm{nm}$ & $d(\mathbf{N}-\mathbf{P t}) / \mathrm{nm}$ & $\delta_{\mathrm{M}}+\mathrm{e}^{[\mathrm{e}]}$ & $\delta_{\mathrm{CN}} / \mathrm{e}^{[\mathrm{e}]}$ \\
\hline \multicolumn{7}{|c|}{$\mathbf{M}=\mathbf{N a}$} \\
\hline Kagome & -5.31 & 0.369 & 0.259 & 0.314 & +0.88 & -0.42 \\
\hline Honeycomb & -5.59 & 0.423 & 0.243 & 0.314 & +0.88 & -0.32 \\
\hline$\left(\mathrm{CN}_{\mathrm{ads}}\right)_{6}-\mathrm{Na}^{+}$ & -5.35 & 0.391 & 0.322 & 0.319 & +0.90 & -0.22 \\
\hline \multicolumn{7}{|c|}{$\mathbf{M}=\mathbf{K}$} \\
\hline Kagome & -5.42 & 0.386 & 0.265 & 0.314 & +0.85 & -0.40 \\
\hline Honeycomb & -5.62 & 0.444 & 0.261 & 0.314 & +0.90 & -0.32 \\
\hline$\left(\mathrm{CN}_{\mathrm{ads}}\right)_{6}-\mathrm{K}^{+}$ & -5.82 & 0.445 & 0.275 & 0.319 & +0.90 & -0.24 \\
\hline
\end{tabular}

[a] Adsorption energy referred to the optimized $(2 \sqrt{3} \times 2 \sqrt{ } 3) R 30^{\circ} \mathrm{CN}$ adlayer and a $\mathrm{M}$ atom in the vacuum.

[b] Distance between the cation and the Pt surface in the optimized structure.

[c] Averaged distance between $\mathrm{M}^{+}$and the $\mathrm{N}$ atom of the $\mathrm{CN}$ groups surrounding the adsorption site.

[d] Average distance from the $\mathrm{N}$ atoms of the adsorbed $\mathrm{CN}$ groups to the $\mathrm{Pt}$ surface.

[e] Mulliken charge of the species in the optimized structure. 
Table 3. Adsorption energy $\left(E_{\mathrm{ads}}\right)$, distance of the adsorbed $\mathrm{H}$ to the surface and Mulliken charge on the adsorbed $\mathrm{H}$ atom $\left(\theta_{\mathrm{H}}=1 / 9\right)$ for the different adsorption sites on $\operatorname{Pt}(111)$.

\begin{tabular}{cccc}
\hline Adsorption site & $E_{\text {ads }} / \mathrm{eV}$ & $d \mathrm{H}-\mathrm{Pt}(111) / \mathrm{nm}$ & Mulliken charge on $\mathrm{H}$ \\
\hline top & -0.54 & 0.159 & -0.22 \\
bridge & -0.58 & 0.105 & -0.28 \\
hollow-fcc & -0.63 & 0.088 & -0.27 \\
hollow-hcp & -0.59 & 0.089 & -0.27 \\
\hline
\end{tabular}


Table 4. Adsorption energy $\left(E_{\mathrm{ads}}\right)$, structural parameters and Mulliken charges for the $\mathrm{CN}$ radical adsorbed on-top on $\mathrm{Pt}(111)$ at low coverage, and for the $\mathrm{H}$ atom adsorbed on the nitrogen atom of the $\mathrm{CN}(\mathrm{Pt}(111)-\mathrm{CNH})$ and at a $\mathrm{Pt}$ site intermediate between bridge and hcp-hollow (NC-Pt(111)-H) in the presence of a low coverage of $\mathrm{CN}_{\mathrm{ad}}$.

\begin{tabular}{|c|c|c|c|c|c|c|c|}
\hline Structure & \multicolumn{2}{|c|}{$E_{\text {ads }} / e V$} & \multicolumn{3}{|c|}{ Atomic distances / nm } & \multicolumn{2}{|c|}{ Mulliken charges } \\
\hline \multirow[t]{2}{*}{$\operatorname{Pt}(111)-\mathrm{CN}^{\mathrm{a})}$} & \multirow{2}{*}{\multicolumn{2}{|c|}{$\mathrm{CN}:-3.59$}} & Pt-C: & $\mathrm{C}-\mathrm{N}$ : & & \multirow{2}{*}{\multicolumn{2}{|c|}{$\mathrm{CN}:-0.20$}} \\
\hline & & & 0.194 & 0.120 & & & \\
\hline \multirow[t]{2}{*}{$\mathrm{Pt}(111)-\mathrm{CNH}^{\mathrm{b})}$} & \multirow[t]{2}{*}{ CNH: -1.86} & \multirow[t]{2}{*}{$\mathrm{H}:-0.92$} & Pt-C: & $\mathrm{C}-\mathrm{N}$ : & N-H: 0.101 & $\mathrm{CN}:+0.38$ & H: -0.14 \\
\hline & & & 0.189 & 0.119 & & & \\
\hline \multirow[t]{2}{*}{$\mathrm{NC}-\mathrm{Pt}(111)-\mathrm{H}^{\mathrm{c})}$} & \multirow[t]{2}{*}{$\mathrm{CN}:-3.54$} & \multirow[t]{2}{*}{$\mathrm{H}:-0.55$} & Pt-C: & $\mathrm{C}-\mathrm{N}$ : & Pt-H:0.100 & $\mathrm{CN}:-0.23$ & $\mathrm{H}:-0.20$ \\
\hline & & & 0.194 & 0.120 & & & \\
\hline
\end{tabular}

a) $\mathrm{CN}$ adsorbed on-top of a $\mathrm{Pt}(111)$ atom, $\theta=1 / 9 .{ }^{\text {b) }} \mathrm{CNH}$ adsorbed on-top of a $\mathrm{Pt}(111)$ atom, $\theta=1 / 9$ (Figure 7B); the value given for $\mathrm{CNH}$ in column two corresponds to the $E_{\text {ads }}$ of a $\mathrm{CNH}$ molecule on $\mathrm{Pt}(111)$ calculated with Eq. 6 , while the value given for $\mathrm{H}$ corresponds to $E_{\text {ads }}$ of a $\mathrm{H}$ atom on the $\mathrm{N}$ atom of an adsorbed $\mathrm{CN}$ moiety calculated with Eq. 5. ${ }^{\text {c) }} \mathrm{CN}$ and $\mathrm{H}$ adsorbed on-top and on a site intermediate between bridge and hcp-hollow, respectively (Figure7C); the value given for $\mathrm{CN}$ in column two corresponds to the $E_{\text {ads }}$ of a $\mathrm{CN}$ radical on $\mathrm{Pt}(111)$ calculated with Eq. 1, while the value given for $\mathrm{H}$ corresponds to $E_{\text {ads }}$ of a $\mathrm{H}$ atom on a $\mathrm{CN}$-free $\mathrm{Pt}$ atom $\left(\theta_{\mathrm{H}}=1 / 9\right)$ of a $\operatorname{Pt}(111)$ surface covered by $1 / 9 \mathrm{ML}$ of $\mathrm{CN}$, calculated with Eq. 4 . 
Table 5. Adsorption energy $\left(E_{\text {ads }}\right)$ and work function difference $(\Delta \Phi)$ in $\mathrm{eV}$ for different configurations and coverages of a $\mathrm{CNH}$ adlayer on $\mathrm{Pt}(111)$ surfaces.

\begin{tabular}{cccc}
\hline$\theta_{\text {adsorbate }}$ & Adsorption site & $E_{\mathrm{ads}(\mathrm{CNH})} / \mathrm{eV}$ & $\Delta \Phi(\mathrm{CNH}) / \mathrm{eV}$ \\
\hline 0.25 & top & -1.86 & -2.66 \\
0.25 & $f c c$ & -2.11 & -0.88 \\
\hline 0.50 & top (zig-zag) & -1.43 & -3.37 \\
0.50 & top (linear) & -1.60 & -2.23 \\
0.50 & $f c c$ (linear) & -1.81 & -0.86 \\
0.50 & top-fcc (mix) & -1.87 & -2.38 \\
\hline 1 & top & -1.04 & -2.69 \\
\hline & $f c c$ & -0.96 & -1.63 \\
\hline
\end{tabular}


Table 6. Adsorption energy and work function difference in $\mathrm{eV}$ for $\mathrm{H}$ adsorbed on $\mathrm{N}$ $(\mathrm{H}-\mathrm{N})$ or on the $\mathrm{Pt}$ surface $(\mathrm{H}-\mathrm{Pt})$ forming different configurations and coverages on $\operatorname{Pt}(111)$ surfaces.

\begin{tabular}{|c|c|c|c|c|c|}
\hline$\theta_{\text {adsorbate }}$ & Adsorption site & $E_{\mathrm{ads}}^{\mathrm{H}-\mathrm{N}} / \mathrm{eV}$ & $E_{\mathrm{ads}}^{\mathrm{H}-\mathrm{Pt}} / \mathrm{eV}$ & $\Delta \Phi_{(\mathrm{H}-\mathrm{N})} / \mathrm{eV}$ & $\Delta \Phi_{(\mathrm{H}-\mathrm{Pt})} / \mathrm{eV}$ \\
\hline 0.25 & top & -1.10 & -0.31 & -2.66 & -2.84 \\
\hline 0.25 & $f c c$ & -1.26 & -0.33 & -0.68 & -1.16 \\
\hline 0.50 & top (linear) & -0.95 & -0.40 & -2.23 & -2.33 \\
\hline 0.50 & fcc (linear) & -1.31 & -0.28 & -0.86 & -0.90 \\
\hline 0.50 & top-fcc (mix) & -1.26 & - & - & - \\
\hline
\end{tabular}


Table 7. Hydrogen and potassium adsorption energy on the $(2 \sqrt{3} \times 2 \sqrt{3}) R 30^{\circ}$ cyanidemodified $\operatorname{Pt}(111)$ surface $\left(E_{\text {ads }}\right)$, structural parameters and Mulliken charges for the structures illustrated in Figure 10.

\begin{tabular}{|c|c|c|c|c|c|}
\hline Structure & $E_{\text {ads }}$ & $e V$ & \multicolumn{2}{|c|}{ Atomic distances / nm } & Mulliken charges \\
\hline \multicolumn{6}{|c|}{$\mathrm{H}_{\text {upd }}$} \\
\hline $\mathrm{Pt}-(\mathrm{CN})_{6}-\mathrm{H}$ & \multicolumn{2}{|c|}{$\mathrm{H}_{\text {upd }}:-0.42$} & \multicolumn{2}{|c|}{ H-Pt: 0.159} & $\mathrm{H}:-0.11 ; \mathrm{CN}:-0.20$ \\
\hline $\mathrm{Pt}-(\mathrm{CN})_{4}-\mathrm{H}$ & \multicolumn{2}{|c|}{$\mathrm{H}_{\text {upd }}:-0.33$} & \multicolumn{2}{|c|}{ H-Pt: 0.159} & $\mathrm{H}:-0.02 ; \mathrm{CN}:+0.38$ \\
\hline $\mathrm{Pt}-(\mathrm{CN})_{3}-\mathrm{H}$ & \multicolumn{2}{|c|}{$\mathrm{H}_{\text {upd }}:-0.36$} & \multicolumn{2}{|c|}{ H-Pt: 0.160} & $\mathrm{H}:-0.03 ; \mathrm{CN}:-0.23$ \\
\hline Pt-CN-K(honeycomb)- & \multirow{2}{*}{\multicolumn{2}{|c|}{$\mathrm{H}_{\text {upd }}:-0.38 \quad \mathrm{~K}:-5.60$}} & \multirow[t]{2}{*}{ H-Pt: 0.159} & K-Pt: & $\mathrm{H}:-0.13 ; \mathrm{CN}:-0.14 ; \mathrm{K}:$ \\
\hline $\mathrm{H}\left(\mathrm{CN}_{6}\right)$ & & & & 0.445 & +0.90 \\
\hline Pt-CN-K(honeycomb)- & \multirow[t]{2}{*}{$\mathrm{H}_{\text {upd }}:-0.30$} & \multirow[t]{2}{*}{$\mathrm{K}:-5.60$} & \multirow[t]{2}{*}{ H-Pt: 0.159} & K-Pt: & $\mathrm{H}:-0.12 ; \mathrm{CN}:-0.33 ; \mathrm{K}:$ \\
\hline $\mathrm{H}\left(\mathrm{CN}_{4}\right)$ & & & & 0.446 & +0.90 \\
\hline \multirow[t]{2}{*}{$\mathrm{Pt}-\mathrm{CN}-\mathrm{K}($ centre $)-\mathrm{H}\left(\mathrm{CN}_{4}\right)$} & \multirow[t]{2}{*}{$\mathrm{H}_{\text {upd }}:-0.49$} & \multirow[t]{2}{*}{ K: -5.98} & \multirow[t]{2}{*}{ H-Pt: 0.159} & K-Pt: & $\mathrm{H}:-0.06 ; \mathrm{CN}:-0.22 ; \mathrm{K}:$ \\
\hline & & & & 0.393 & 0.86 \\
\hline \multicolumn{6}{|c|}{$\mathrm{H}$ protonating $\mathrm{CN}$} \\
\hline $\mathrm{Pt}-\mathrm{CN}-\mathrm{Hx} 1$ & \multicolumn{2}{|c|}{$\mathrm{H}:-2.28$} & \multicolumn{2}{|c|}{ H-N: 0.113} & $\begin{array}{c}\mathrm{H}:-0.15 ; \mathrm{CN}(\mathrm{H}):+0.25 ; \\
\left.\mathrm{CN}---(\mathrm{H}):-0.03 ; \mathrm{CN}:-0.18^{\mathrm{a}}\right)\end{array}$ \\
\hline Pt-CN-Hx3 geom-1 & \multicolumn{2}{|c|}{ H: -1.94} & \multicolumn{2}{|c|}{ H-N: 0.108} & $\begin{array}{c}\mathrm{H}:-0.11 ; \mathrm{CN}(\mathrm{H}):+0.10 \\
\mathrm{CN}:-0.10\end{array}$ \\
\hline Pt-CN-Hx3 geom-1 & \multicolumn{2}{|c|}{$\mathrm{H}:-1.73$} & \multicolumn{2}{|c|}{ H-N: 0.105} & $\begin{array}{c}\mathrm{H}:-0.09 ; \mathrm{CN}(\mathrm{H}):+0.10 \mathrm{CN}: \\
-0.23\end{array}$ \\
\hline
\end{tabular}

a) $\mathrm{CN}(\mathrm{H})$ stands for protonated $\mathrm{CN}_{\mathrm{ad}}$, $\mathrm{CN}---(\mathrm{H})$ stands for the $\mathrm{CN}$ that makes a $\mathrm{H}$-bond with the adsorbed $\mathrm{H}$ atoms, and $\mathrm{CN}$ are the remaining $\mathrm{CN}_{\mathrm{ad}}$, that are not involved in the bonding with the $\mathrm{H}$ atom. 
Click here to download high resolution image
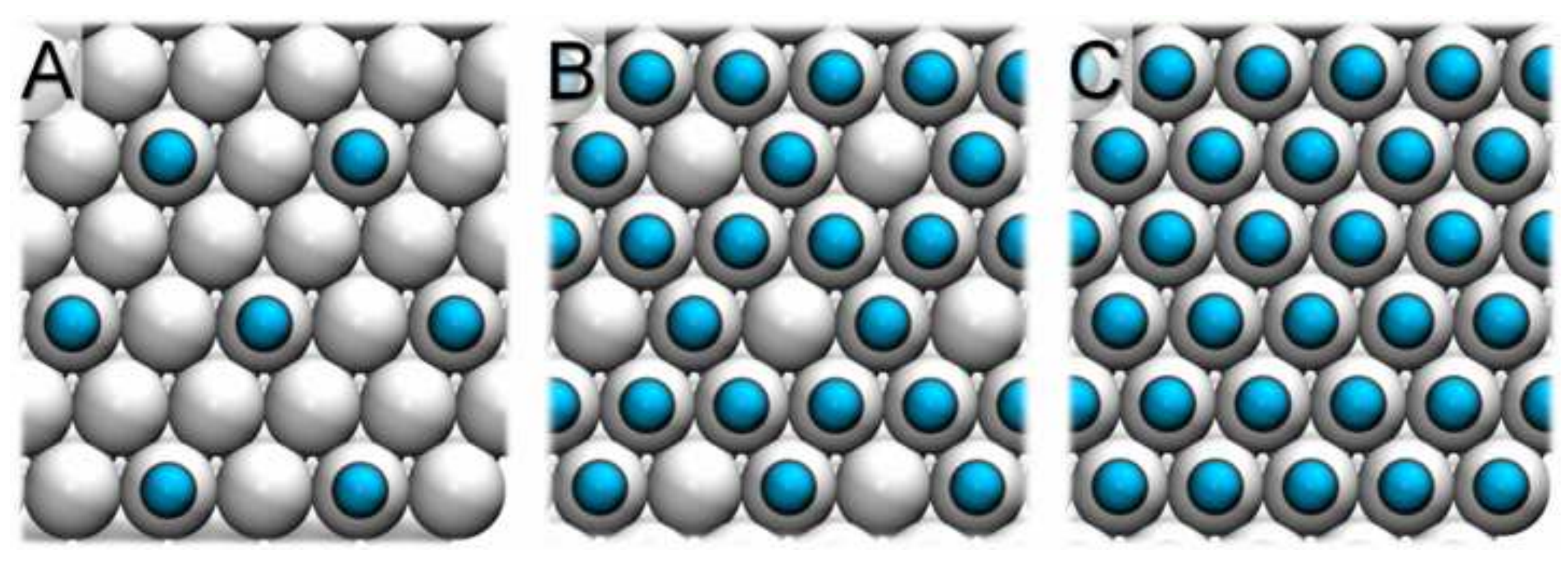
Click here to download high resolution image
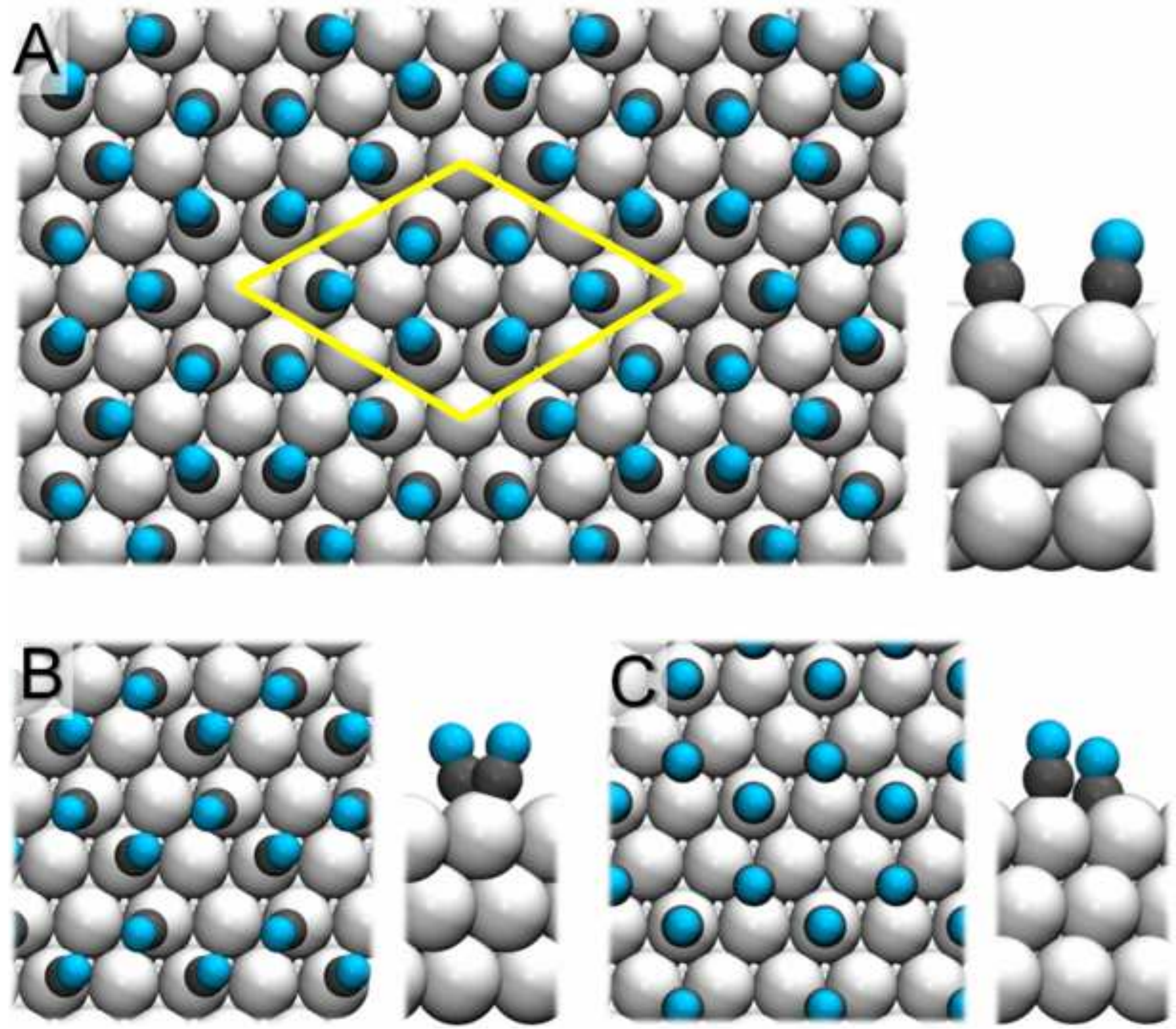

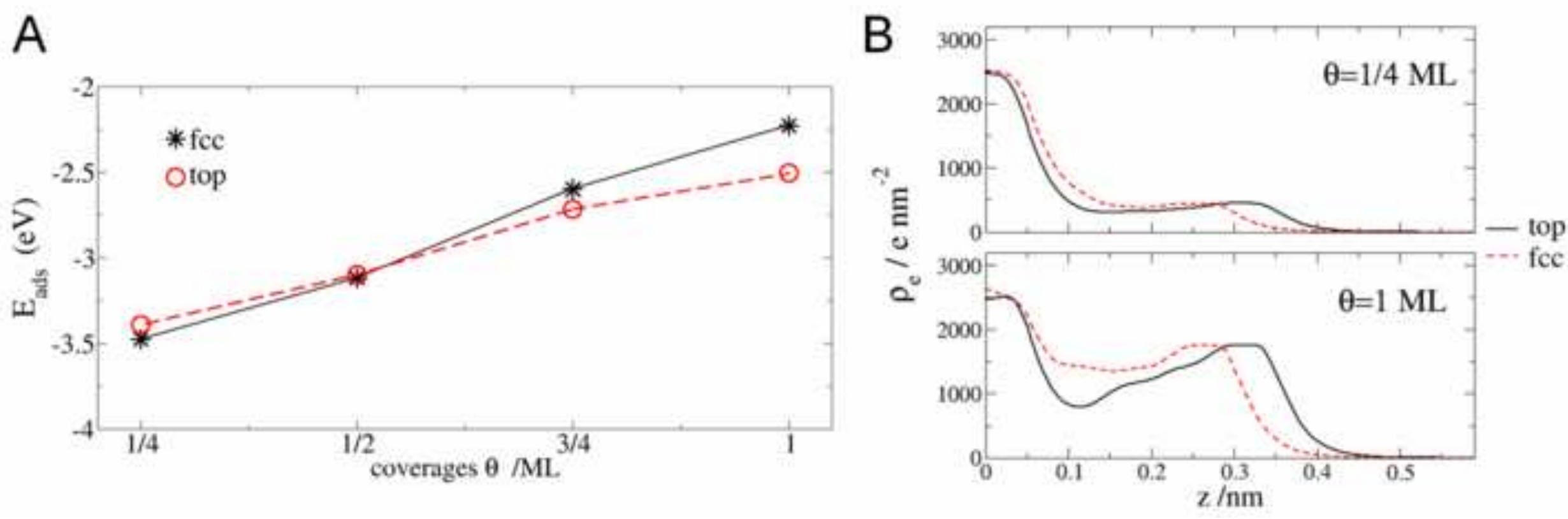
Click here to download high resolution image

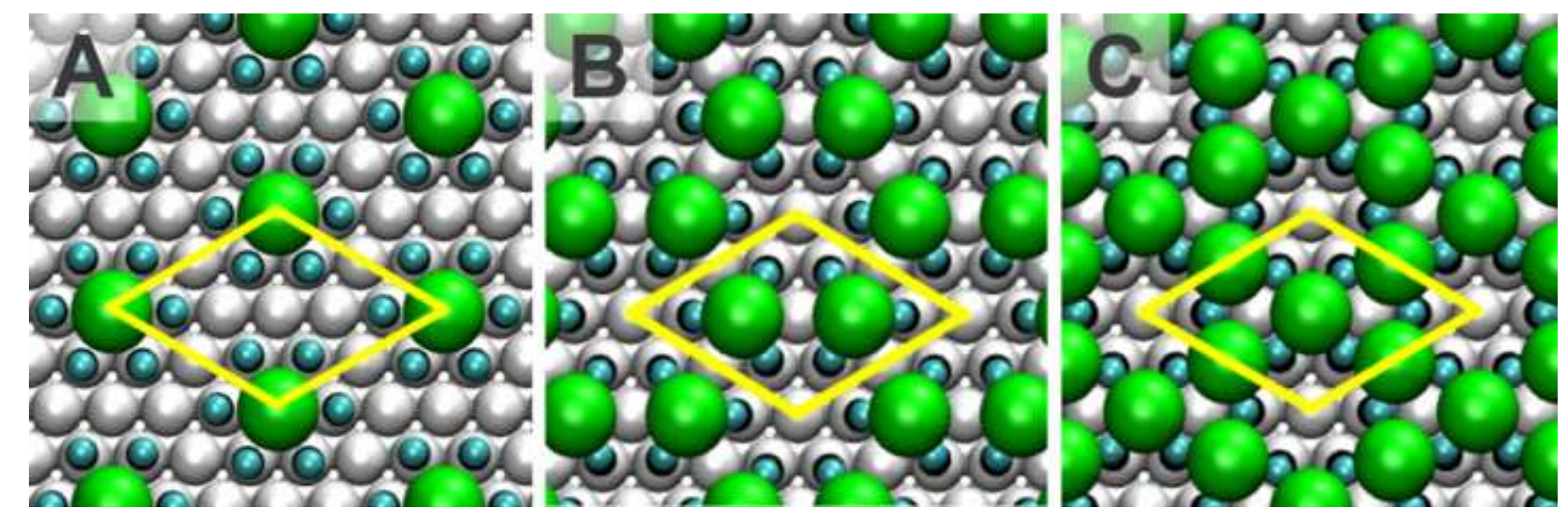



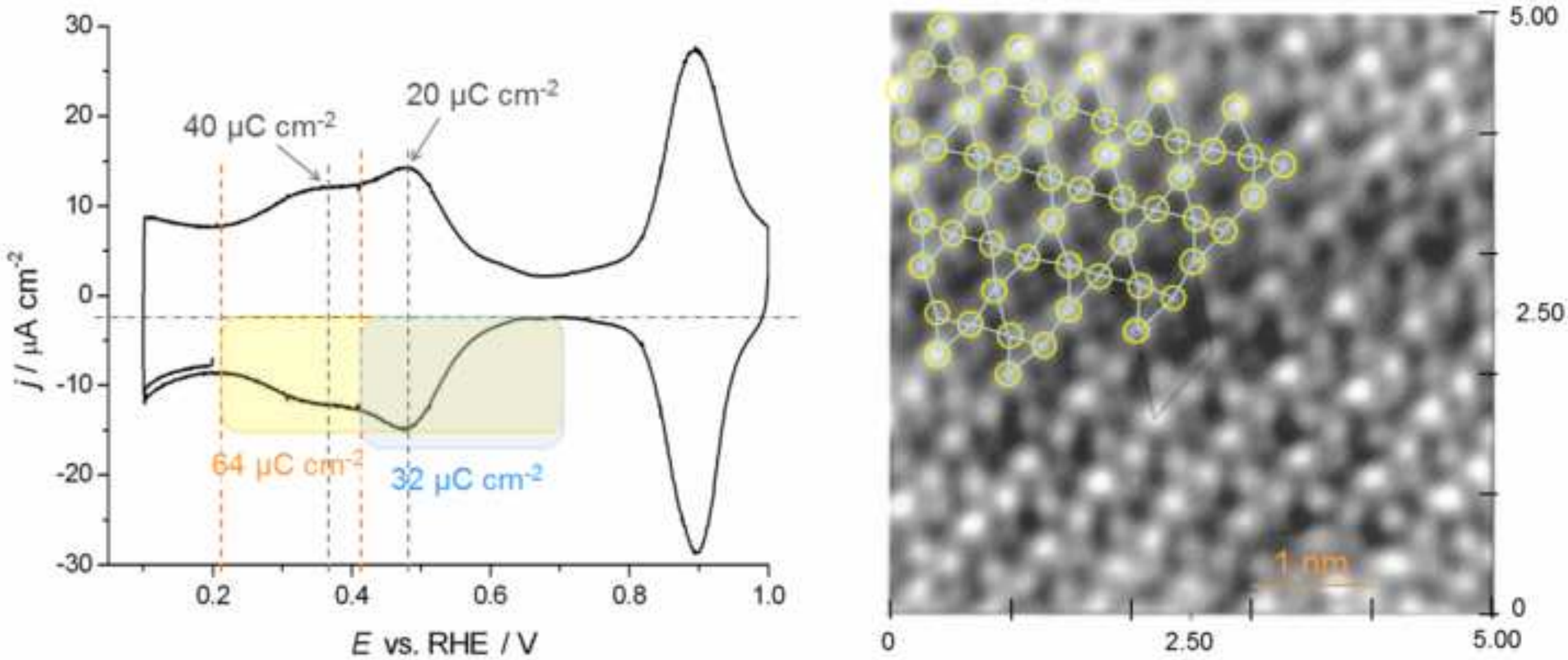

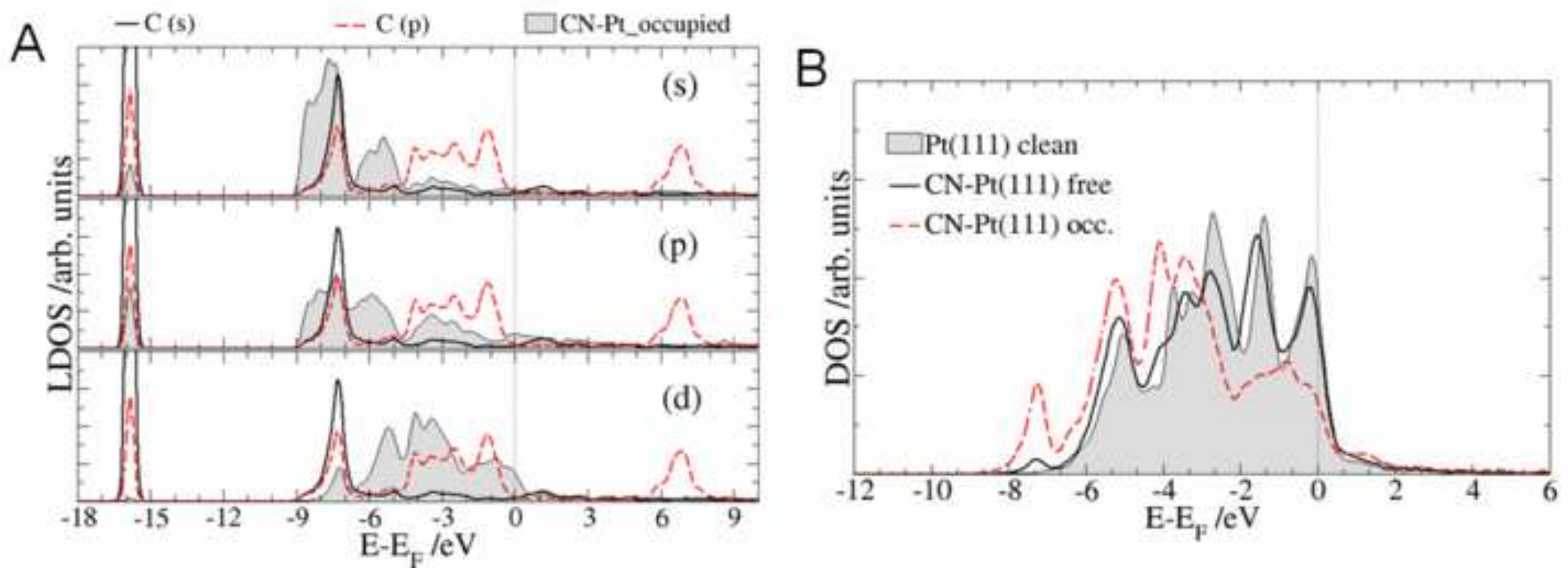

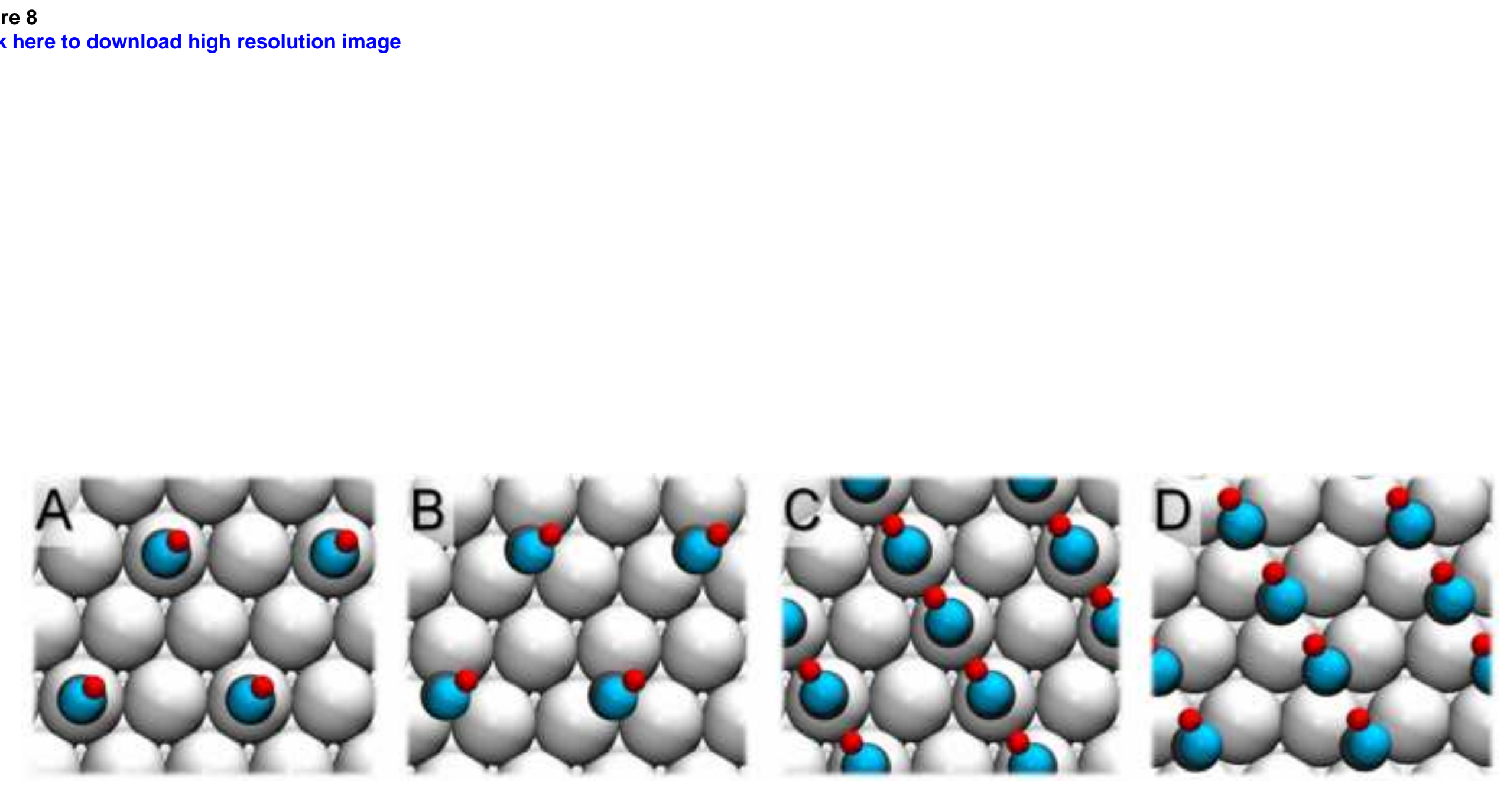

\section{here to download high resolution image}

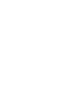

.
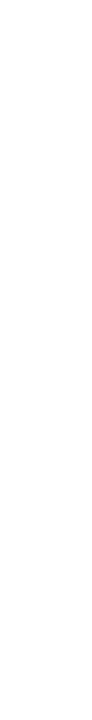

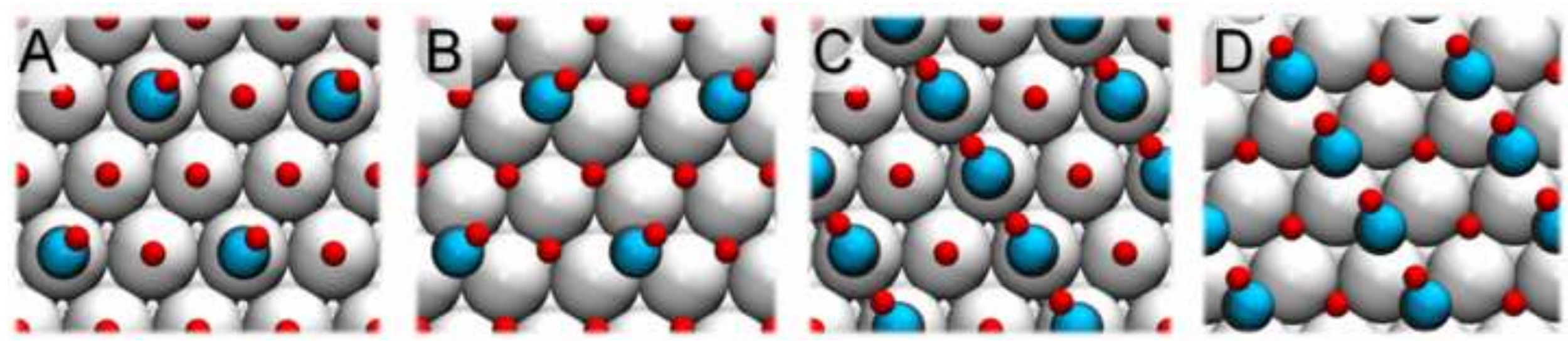
ACrescos Acose

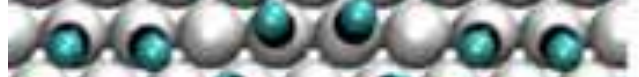
- escose oxolorer. oscosesco baceroral - percose

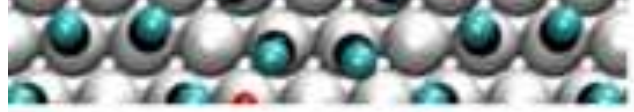
Diencros Dorborsor orcinar bous orolos 400 - cos 30 bor D cola bor 010 aroncios Sorolores anereser Govodoror - coló 9 Dororor Uue cLe roroporor o ous a 10.0.0.0. Cus cos

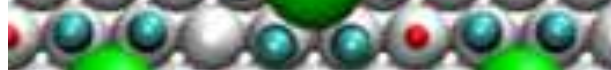
hi mista
Borerar escosere bicosor. oroscos sorolor. exicheresce biarsorar yoscos

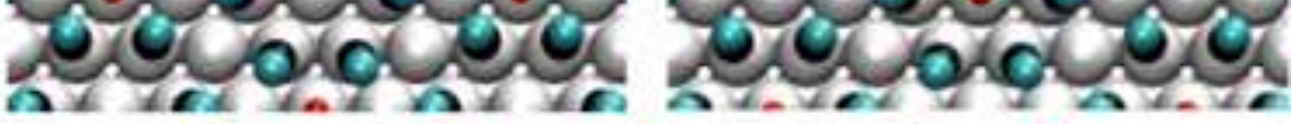

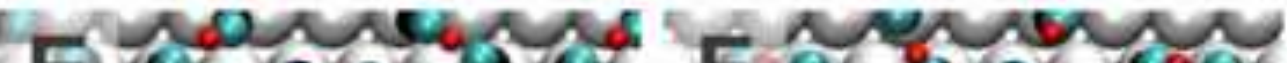

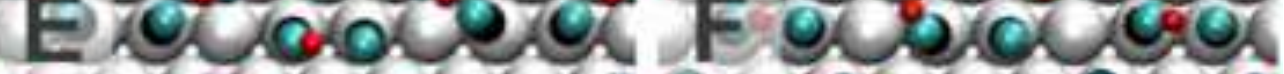

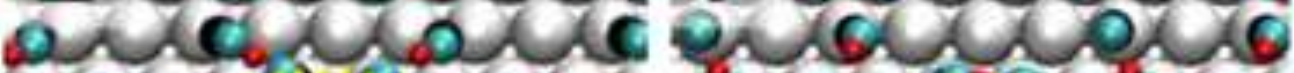

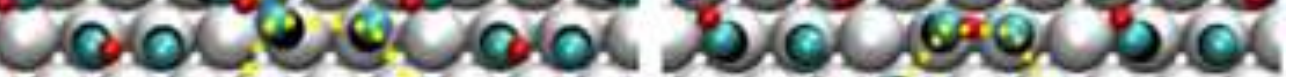

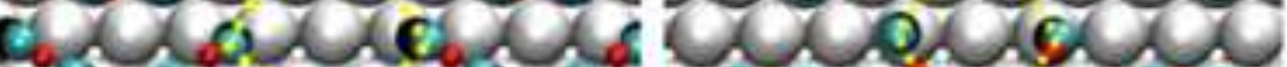

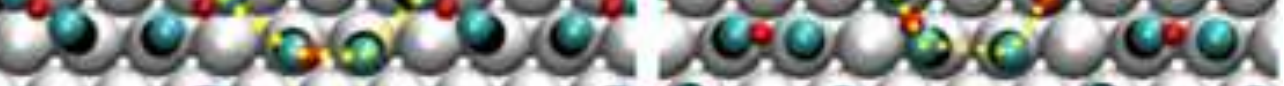

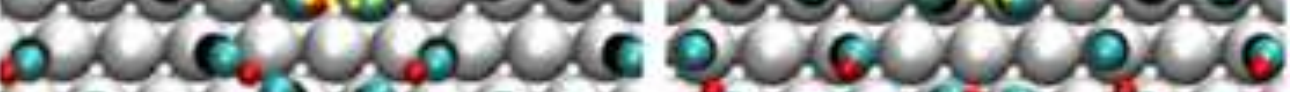
rolos

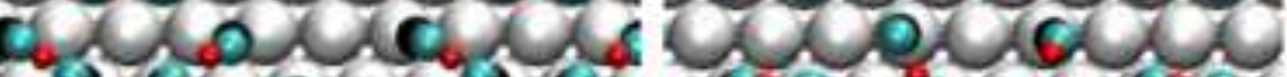

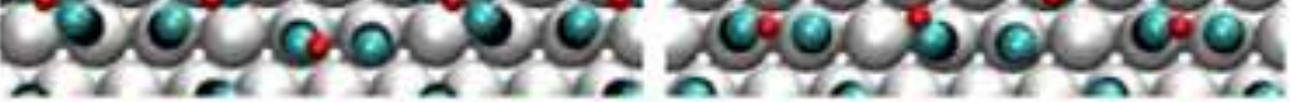
Horions vode p bxa

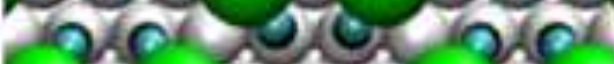
-

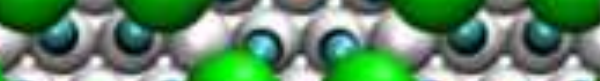
Dora plod

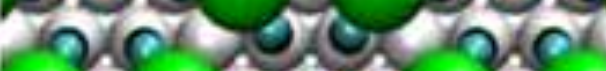
oreacer

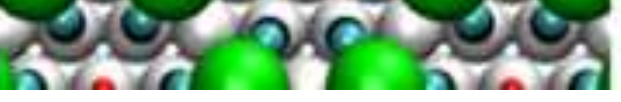

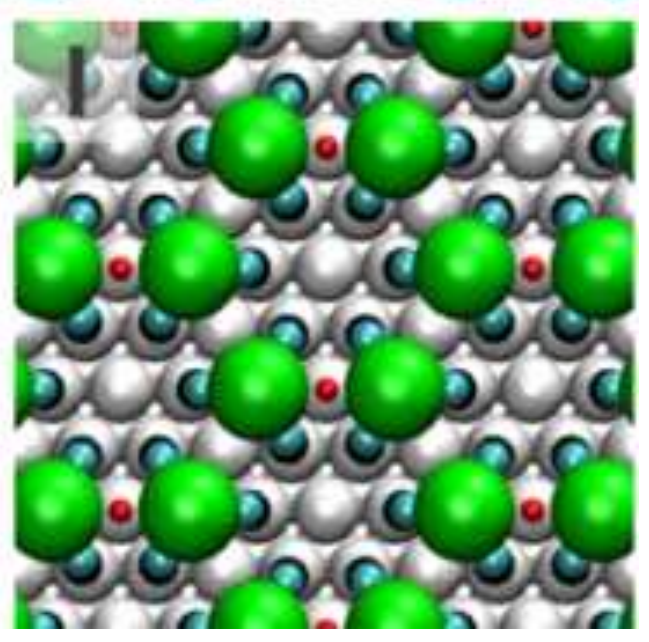




\section{Supporting Information for publication
Click here to download Supplementary Materials: SI, Escudero-Escribano et al, definitive.doc}

$\sqrt{3}$

$\sqrt{2}$

(1)

(1)

(1) (1) (1) (1) . . . . . . . . . . . . 
Copyright permission for publisher, corresponding to Figure 5B
Click here to download Supplementary Materials: copyright permission.pdf 